\title{
A Rare Case of Saudi Girl with Recurrent Strokes and Abnormal Multiple Thrombophilia
}

Ibrahim Alharbi ${ }^{1^{*}}$, Wijdan Al Zamzami ${ }^{2}$ and Elham Alharbi ${ }^{2}$

${ }^{1}$ King Fahad Armed Forces Hospital, Jeddah, Saudi Arabia

${ }^{2}$ Faculty of Medicine, Umm Al-qura University, Makkah, Saudi Arabia

*Corresponding author: Ibrahim Alharbi, King Fahad Armed Forces Hospital, Jeddah, Saudi Arabia' Tel: +966-55-5609700; E-mail: ialhrbi4@gmail.com

Received date: July 25, 2018; Accepted date: August 20, 2018, Publication date: August 27, 2018

Copyright: (02018 Alharbi I, et al. This is an open-access article distributed under the terms of the Creative Commons Attribution License, which permits unrestricted use, distribution, and reproduction in any medium, provided the original author and source are credited.

\begin{abstract}
Recurrent multiple symptomatic strokes are infrequent in paediatric population. The causes for such events are usually cardiac, multiple inherited thrombophilia; such as Protein C, Protein S, Antithrombin III, and Antiphospholipid Syndrome, and other causes. We report a case of Saudi Girl who presented in December 12, 2017 with right sided Hemiparesis. Central Nervous System (CNS) imaging revealed left sided ischemic infarction. Investigations showed that in fact she has multiple inherited thrombophilia risk factors. She was found to have homozygous mutations in Prothrombin Gene Complex FII (G20210A), a mutation in the gene encoding Plasminogen Activator Inhibitor-1. Heterozygous mutations in 2 Methylene Tetrahydrofolate Reductase (MTHFR): c.677C >T and c.1298A > c. She was also found to have high Lipoprotein A levels $(656 \mathrm{mg} / \mathrm{L})$ which is also a known risk factor for arterial ischemia specifically. We concluded that having multiple inherited Thrombophilia mutations can result in increased risk of severe and symptomatic Ischemic infarctions in children.
\end{abstract}

Keywords: Stroke; Ischemic infarction; Prothrombin gene mutation; Thrombophilia; Plasminogen activator inhibitor-1

\section{Introduction}

Thromboembolic events in children are not uncommon conditions. The majority of these events happen in the presence of certain risk factors. There are acquired and congenital risk factors. Among the congenital risk factors; certain mutations that affect specific genes involved in the synthesis of certain proteins that are involved in normal coagulation and hemostasis. There are physiological, naturally occurring anticoagulants that circulate in blood and their role is to maintain blood flow. Also some of them are involved in the fibrinolytic system. Defect in these mechanisms can lead to Cardiovascular Diseases (CVD) and Cerebrovascular Accidents (CVAs) that are considered to be the leading cause of death in adults. In Pediatric patients, it is very rare with an estimated incidence of about 1 per 100,000 per year [1].

There are many studies focused on the naturally occurring anticoagulants, hemostatic markers and also on prothrombin gene polymorphisms as risk factors for stroke. They are all involved in stroke pathogenesis in significant number children with strokes. They are responsible for stroke and other thromboembolic conditions in at least $10 \%-30 \%$ of all pediatric stroke patients [2].

Spontaneous unprovoked strokes have been reported in children with Prothrombin Gene mutations. FII G20210A allele within the 3'untranslated region of the prothrombin (PT) gene. Also, mutations resulting in defects of the Methylene Tetrahydrofolate Reductase (MTHFR) molecule were found to be associated with spontaneously occurring childhood strokes [3]. Furthermore, an elevated level of lipoprotein (a) has been identified as a genetically determined risk factor for children with strokes beyond the neonatal period [4]. In addition, it has been found that patients suffering from deep venous thrombosis and in symptomatic childhood carriers of the FV G1691A gene mutation, risk of strokes is increased and has been linked to increased levels of plasminogen activator inhibitor-1which leads to diminished fibrinolytic function and activity $[5,6]$.

\section{Case Presentation}

A 9-year-old girl came to emergency department on February 13, 2018 complaining of right hand weakness and loss of grip. She has similar attacks of sudden onset of weakness over last few months. No family history of thrombosis or stroke at a young age. She was admitted, and MRI brain was done. It has shown scattered left cerebral preventricular/subcortical white matter recent ischemic foci, representing ischemic infarction. She initially was started on Aspirin 5 mg per kilogram daily. Then she was started on Low Molecular Weight Heparin $1 \mathrm{mg} / \mathrm{kg} /$ day subcutaneously. Thrombophilia work up was initiated. It was found that she has homozygous mutation in the Prothrombin Gene Complex (G20210 G>A). She was also found to have a mutation in the gene coding for Plasminogen Activator Inhibitor-1 (genotype 4G/4G homozygous). Also she has mutations in the genes endoing for Methylene tetrahydrofolate reductase (MTHFR) (c.677c > T: genotype / T heterozygous) and (c.1298A >c: genotype A/C heterozygous).

\section{Discussion}

Stroke in children is not a rare phenomenon [7]. Krishnamurthi et al. [8] found that in 2013 alone; the prevalence of Paediatric Ischemic strokes (IS) was 97,792 (59.3\%) and prevalence of haemorrhagic stroke (HS) was 67,621 (40.7\%). There was an increase of 35\% since 1990. Of all paediatric strokes, mortality was $19.9 \%$, significant disability was present in $40 \%$ [8]. Ischemic stroke in children can occur as a result of mainly 3 etiologic categories: infections, congenital heart diseases, and inherited or acquired hyper coagulable conditions. Inherited 
Hypercoagulable conditions (Inherited Thrombophilia) represent $10 \%-25 \%$ of all causes of ischemic strokes in children. Yet, approximately $30 \%$ of children with strokes have no identifiable established risk factors [9].

Congenital Hypercoagulable states can be divided into two types:

1. Deficiency of Direct Natural Anticoagulants (Like Protein C, Antithrombin)

2. Deficiency of Antifibrinolytics (Such as deficiency of Plasminogen Activator Inhibitor-2)

This patient has deficiency of both types. She has a Prothrombin Gene Mutation G20210A as well as Plasminogen Activator Inhibitor-1. Both of which are proven risk factors for the development of thromboembolic events. Among inherited thrombophilia, only homozygous Methylene Tetra-Hydrofolate Reductase (MTHFR) C677T Polymorphism has been shown to independently increase the risk of stroke [10]. However, combinations of multiple inherited thrombophilia can increase the risk of first and recurrent strokes in children. Prothrombin Gene Mutation G20210A is the second most common cause of inherited thrombophilia after Factor V Leiden. The carrier rate of FIIG20210A is about $3 \%$ of the general population. In a systematic review that looked at global prevalence of FII G20210, Dziadosz et al. [11] found that it varies from one to another and has a carrier rate of $15.2 \%$ in some societies [12]. In children, it has been found that FII G20210A is associated with $30 \%$ of Central Nervous System (CNS) events and 67\% of all arterial events [11]. Unlike other causes of inherited thrombophilia, especially Factor $\mathrm{V}$ Leiden mutation, FII G20210A is associated more with arterial rather than venous thrombosis [13]. It has also been observed by De Stephano et al. [14] that heterozygous carriers of FII G20210A are at risk for recurrent thromboembolism. In a review of a cohort of patients with recurrent thromboembolism the conclusion was if FII G20210A carrier individuals experience more than one episode of thromebolic events then they should be started on anticoagulation to prevent complications [14].

There are two Plasminogen Activator Inhibitors in the fibrinolytic pathway. The first, Plasminogen activator inhibitor-1 which is a serine protease inhibitor (serpin) that inhibits Tissue plasminogen Activator (tPA) and Urokinase (also known as Urokinase-Type Plasminogen Activator uPA). Deficiency of PIA-1 actually leads to increase risk of bleeding because of the increased levels of activation of plasminogen to plasmin which will lead to excessive fibrinolysis [15]. On the other hand, increased levels of PIA-1 leads to increased risk of thrombosis [16]. There are other roles of PIA-1 in the process of vascular inflammation, atherosclerosis, and myocardial infarction [17]. PIA-1 gene is located on chromosome $7 \mathrm{q} 21.3$ [18]. There are different polymorphisms of PIA- 1 . The most common is $4 \mathrm{G} / 5 \mathrm{G}$ polymorphism in the promoter region. $4 \mathrm{G} / 5 \mathrm{G}$ polymorphism is associated with increased PPAI-1 activity and increased risk of thrombosis risk. Initial studies failed to find a strong association between PAI-1 4G/5G polymorphism and stroke [19]. However, further and subsequent studies showed that, although not as an independent risk factor for stroke, PAI-1 4G/5G polymorphism can cause a stroke when associated with other risk factors [20]. Plasminogen Activator Inhibitor-2 (PIA-2) is a 393-amino acid protein that functions as an inhibitor of both tPA and uPA [21]. The gene encoding PIA-2 is on chromosome 18q21-23 [22].

There was also an increased level of Lipoprotein-a in this patient. $\mathrm{Lp}(\mathrm{a}), \quad$ an atherogenic, hypofibrinolytic, cholesterol-carrying lipoprotein. Studies have shown that in homozygous Plasminogen Activator Inhibitor-1 4G/5G Polymorphism; levels of Lipoprotein (a) are increased. Levels greater than $30 \mathrm{mg} / \mathrm{dl}$ are associated with atherosclerosis risk as well as ischemic strokes [23].

The heterozygosity for the Methylene Tetrahydrofolate Reductase (MTHFR) gene (C677T and A1298C) does not represent any risk for stroke. In fact, even homozygous MTHFR is not enough to initiate a stroke or first thromboembolic event in patients without presence of other risk factors [24]. The more common variant MTHFR C677T is found in as much as $61 \%$ of the population in some studies [25].

\section{Conclusion}

Presence of 4G/5G PAI-1 polymorphism, Prothrombin Gene Mutation (FII G20210A, as well as elevated Lipoprotein-a levels present a significant risk factors for first and subsequent strokes. This is probably the first case in children with all these 3 risk factors combined which justified anticoagulation therapy for life.

What is the evidence for management of patients with combined thrombophilia? How long would you treat? There is no consensus on duration of therapy. Several factors are to be considered when making a decision regarding initiation and duration of anticoagulation therapy; such as age, family history, site, severity of thromboembolic event. If the risk of recurrence is high; the suggestions are to continue for at least 2 years from the last event [26].

\section{References}

1. Tsze DS, Valente JH (2011) Pediatric stroke: A review. Emerg Med Int 1-10.

2. Johnson MJM (2005) Development of hemostasis in the fetus. Thromb Res 115: 55-63.

3. Andrew M, Vegh P, Johnston M (1992) Maturation of the hemostatic system during childhood. Blood 80: 1998-2005.

4. Miles LA, Fless GM, Levin EG, Scanu AM, Plow EF (1989) A potential basis for the thrombotic risks associated with lipoprotein (a). Nature 339: 301-303.

5. Alluri RV, Mohan V, Komandur S, Chawda K, Chaudhuri JR, et al. (2005) MTHFR C677T gene mutation as a risk factor for arterial stroke: a hospital based study. Eur J Neurol 12: 40-44.

6. Vague IJ, Valadier J, Alessi MC (1987) Deficient t-PA release and elevated $\mathrm{PA}$ inhibitor levels in patients with spontaneous or recurrent deep venous thrombosis. Thromb Haemost 57: 67-72.

7. Margaglione M, Cappucci G, Colaizzo D (1998) The PAI-1 gene locus $4 \mathrm{G} / 5 \mathrm{G}$ polymorphism is associated with a family history of coronary artery disease. Arterioscler Thromb Vasc Biol 18: 152-156.

8. Krishnamurthi RV (2015) Stroke prevalence, mortality and disabilityadjusted life years in children and youth aged 0-19 years: data from the global and regional burden of stroke 2013. Neuroepidemiology 45: 177-189.

9. Fox CK, Johnston SC, Sidney S, Fullerton HJ (2012) High critical care usage due to pediatric stroke: results of a population-based study. Neurology 79: 420-427.

10. Ganesan V, Prengler M, McShane MA, Wade AM, Kirkham FJ (2003) Investigation of risk factors in children with arterial ischemic stroke. Ann Neurol 53: 167-173.

11. Dziadosz M, Baxi LV (2016) Global prevalence of prothrombin gene mutation G20210A and implications in women's health: a systematic review. Blood Coagul Fibrinolysis 27: 481-489.

12. Göttl UN, Sträter R, Heinecke A, Junker R, Koch HG, et al. (1999) Lipoprotein (a) and genetic polymorphisms of clotting factor V, 
Citation: Alharbi I, Zamzami WA, Alharbi E (2018) A Rare Case of Saudi Girl with Recurrent Strokes and Abnormal Multiple Thrombophilia . J

prothrombin, and methylenetetrahydrofolate reductase are risk factors of spontaneous ischemic stroke in childhood. Blood 94: 3678-3682.

13. Young G, Johnson MM, Gill JC, Dimichele DM, Tarantino MD, Abshire T, et al. (2003) Clinical manifestations of the prothrombin G20210A mutation in children: a pediatric coagulation consortium study. J Thromb Haemost 1: 958-962.

14. Stefano DV, Martinelli I, Mannucci PM, Paciaroni K, Rossi E, et al. (2001) The risk of recurrent venous thromboembolism among heterozygous carriers of the G20210A prothrombin gene mutation. Br J Haematol 113: 630-635.

15. Schleef RR, Higgins DL, Pillemer E (1989) Bleeding diathesis due decreased functional activity of type I plasminogen activator inhibitor. J Clin Invest 83: 1747-1752.

16. Saito H (1988) a 2 -plasmin inhibitor and its deficiency states. J Lab Clin Med 112: 671-678.

17. Aso H (2007) Plasminogen activator inhibitor (PAI)-1 in vascular inflammation and thrombosis. Front Biosci 12: 2957-2966.

18. Mimuro J (1991) Type 1 plasminogen activator inhibitor: its role in biological reactions. Rinsho Ketsueki 32: 487-489.

19. Ridker PM, Hennekens CH, Lindpaintner K, Stampfer MJ, Miletich JP (1997) Arterial and venous thrombosis is not associated with the 4G/5G polymorphism in the promoter of the plasminogen activator inhibitor gene in a large cohort of US men. Circulation. 95: 59-62.
20. Wiklund PG, Nilsson L, Ardnor SN, Eriksson P, Johansson L, et al. (2005) Plasminogen activator inhibitor- $14 \mathrm{~g} / 5 \mathrm{~g}$ polymorphism and risk of stroke replicated findings in two nested case-control studies based on independent cohorts. Stroke 36: 1661-1665.

21. Sprengers ED, Kluft D (1987) Plasminogen activator inhibitors. Blood 69: 381-387.

22. Ye RD, Aherns SM, Beau LMM (1989) Structure of the gene for human plasminogen activator inhibitor-2. The nearest mammalian homologue of chicken ovalbumin. J Biol Chem 264: 5495-5502.

23. Dai W, Long J, Cheng Y, Chen Y, Zhao S (2018) Elevated plasma lipoprotein (a) levels were associated with increased risk of cardiovascular events in chinese patients with stable coronary artery disease. Sci Rep 8: 7726.

24. Bezemer ID, Doggen CJ, Vos HL (2007) No association between the common MTHFR677C- $>\mathrm{T}$ polymorphism and venous thrombosis: Results from the MEGA study. Arch Intern Med 167: 497-501.

25. Frosst P, Blom HJ, Milos R (1995) A candidate genetic risk factor for vascular disease: a common mutation in methylenetetrahydrofolate reductase. Nat Genet 10: 111-113.

26. (1997) Inherited thrombophilia: Memorandum from a joint WHO/ international society on thrombosis and haemostatis meeting. Bull World Health Org 75: 177-189. 